\title{
Personality and Clinical Dimensions of Pathological Gamblers. A Pilot Study
}

\section{Giuseppe Craparo ${ }^{*}$}

\author{
Alessio Gori² \\ Giuseppe Iraci Sareri ${ }^{3}$ \\ Ugo Pace ${ }^{1}$
}

1 Faculty of Human and Social Sciences, Kore University of Enna, Italy
2 Department of Psychology, University of Florence, Italy
${ }^{3}$ Incontro Cooperative, Pistoia, Italy
${ }^{*}$ Corresponding Author Email Address: giuseppe.craparo@unikore.it

Doi:10.5901/mjss.2015.v6n4s3p612

\section{Abstract}

Gambling disorder is characterized by a persistent and recurrent maladaptive gambling behavior. In this paper, we analyzed the psychopathological dimensions of a group of gamblers and investigated the potential predictors of good/poor therapeutic outcomes. A total of 45 gamblers, between 23 and 69 years old $(M=45.73, S D=10.93)$, were recruited in the following structures for the treatment of pathological gambling: the "Incontro" cooperative of Pistoia (Italy) and the "Orthos" community of Siena (Italy). We found significant correlations among SOGS, TAS-20/DIF, DES, and any clinical dimensions of MMPI-2. Nevertheless the several limits, the present study confirmed the impulsive nature of pathological gambling. Moreover, the results showed positive correlations among impulsivity, dissociation, and affect dysregulation (measured by the first factor of the TAS-20).

\section{Introduction}

In the DSM-5, gambling disorder is characterized by a "persistent and recurrent maladaptive gambling behavior that disrupts personal, family, and/or vocational pursuit" (American Psychiatric Association, 2013, p. 586). Subjects with this disorder may exhibit several symptoms (Criterion A), such as a need to gamble with increasing amounts of money to achieve the desired excitement, need to gamble when feeling distressed, and persistent thoughts regarding gambling experiences.

It is well known that pathological gamblers present high rates of mood and substance use disorders (Lorains, Cowlishaw \& Thomas, 2012), although few researchers have actually assessed the rates of these or other psychiatric conditions. For example, Quigley and colleagues (2014), showed that $34 \%$ of gamblers in their study had major depression. Other studies showed a prevalence of other psychopathological conditions among pathological gamblers, including panic disorder, attention-deficit hyperactivity disorder, and various impulse control disorders (Davis and Loxton, 2013; Suomi, Dowling, and Jackson, 2014).

In this paper, we analyze the psychopathological dimensions of a group of gamblers and investigate the potential predictors of good/poor therapeutic outcomes.

\section{Method}

\subsection{Participants}

A total of 45 gamblers were recruited in the following structures for the treatment of pathological gambling. The participants were between 23 and 69 years old $(M=45.73, S D=10.93)$. With respect to the level of education, 5 subjects (11\%) were elementary school graduates, 13 (29\%) subjects had a middle school diploma, 22 (49\%) subjects had a high school diploma, 3 (2\%) had a bachelor's degree, and 2 (4\%) had a master's degree.

Regarding their relationship status, 14 participants declared themselves to be single, 1 was engaged, 19 were 
married, and 11 were divorced.

\subsection{Procedure}

The participants of this study were recruited into the following structures for the treatment of pathological gambling: the "Incontro" cooperative of Pistoia (Italy) and the "Orthos" community of Siena (Italy). Access to and retention in the treatment by the gamblers, in the two above-mentioned realities, are usually voluntary, and the treatment usually begins after assessing the severity of the pathological gambling and evaluating the presence of other forms of addiction, such as alcoholism and drug addiction. During the first part of the treatment (15 days), the severity of the gamblers' addiction was assessed through clinical interviews and self-report measures.

In order to assess the personality dimensions associated with a negative attitudes toward mental health treatments we divided the sample into two groups: 1) subjects who obtained a high T score on TRT scale; 2) subjects who obtained a low T score on TRT scale.

Assessment procedures were carried out by diverse professional figures (psychologists, psychiatrists, and psychotherapists). All of the subjects included in the research met the criteria for a diagnosis of pathological gambling according to the DSM criteria. The self-report measures together with a demographic questionnaire (asking about age, sex, weight, and height) were administered to the participants in a group setting.

A plain language statement attached to the front of the questionnaires explaining the nature of the study. The participants were asked to be as honest and spontaneous as possible in their responses and were assured of their anonymity and confidentiality. All of the participants signed an informed consent after an intake assessment. The data collected were used exclusively for scientific purposes.

\subsection{Measures}

The South Oaks Gambling Screen (SOGS, Lesieur \& Blume 1987) is a 20-item self-report questionnaire to evaluate probable pathological gambling. The SOGS has a good validity and a good internal reliability (Cronbach alpha 0.86$)$, also for the Italian version (Cronbach alpha 0.81) (Guerreschi \& Gander, 2000).

The Twenty-Item-Toronto Alexithymia Scale (TAS-20; Bagby, Parker, \& Taylor, 1994a, 1994b) is a 20-item selfreport measure, and a higher score indicates higher levels of alexithymia. It is possible to distinguish three factors: 1 ) difficulty modulating and identifying feelings (DIF), 2) difficulty describing one's feelings to others (DDF), and 3) externally oriented thinking (EOT). Cutoff scores are as follows: $\leq 50=$ no alexithymia, $51-60=$ borderline alexithymia, and $\geq 61=$ alexithymia. The TAS-20 has shown adequate validity and reliability $(a=0.81 ; r=0.77)$. Likewise, the Italian version (Bressi et al., 1996) presents a good internal reliability (Cronbach's $a=0.81$ ).

Barrat Impulsiveness Scale (BIS-11; Patton et al., 1995). The Barratt Impulsiveness Scale-11 is a 30-item selfreport questionnaire designed to assess general impulsiveness, taking into account the multi-factorial nature of the construct. The structure of the instrument allows for the assessment of six first-order factors (attention, motor, self-control, cognitive complexity, perseverance, and cognitive instability) and three second-order factors: attentional impulsiveness, motor impulsiveness (motor and perseverance), and nonplanning impulsiveness (self-control and cognitive complexity). The Italian version presents a good internal reliability (Cronbach's a $=0.79$ ) (Fossati et al., 2001).

The Minnesota Multiphasic Personality Inventory - 2 (MMPI-2; Butcher et al., 1989) is a 567-item self-report questionnaire used to evaluate various psychopathological aspects (e.g., anxiety, depression, schizophrenia, and hysteria). Elevated T-scores ( $\geq 65)$ for each scale reflect the presence of various psychopathology dimensions. Italian version presents a good internal validity (Pancheri \& Sirigatti, 1995).

\subsection{Data analysis}

Descriptive statistics for all variables were examined, and statistical results of demographic variables based on percentages, scale means, and standard deviations were presented. A series of two-tailed Pearson linear correlations and linear regression were conducted to test relations among the variables under investigation. Furthermore, a series of t-tests was performed to verify the differences between the two groups: 1) subjects who obtained a high T score on TRT scale; 2) subjects who obtained a low T score on TRT scale. The statistical package SPSS 19.0 for Windows was used for all the analyses (SPSS, Chicago, IL, USA). 


\subsection{Results}

Mean score and standard deviation for the SOGS suggest a pathological condition $(M=12.82, S D=3.11)$. The DES mean score was not significant for a dissociative functioning $(M=19.58, S D=10.39)$. Regarding the presence of alexithymic traits, our group obtained a mean score classified as "borderline" ( $M=57.16, S D=10.85)$ and the following mean scores on its subscales: TAS-20/DIF ( $M=19.56, \mathrm{SD}=5.79)$, TAS-20/DDF $(\mathrm{M}=15.71, \mathrm{SD}=4.78)$, and TAS20/EOT ( $M=22.11, S D=4.39$ ). Within a group, 18 subjects (40\%) were alexithymic, 11 were (24\%) not alexithymic, and $16(36 \%)$ were borderline. Regarding the BIS scores, a group obtained high mean scores in both the BIS total score ( $M=$ $74.49, \mathrm{SD}=8.85)$ and its three factors: $\mathrm{BIS}-\mathrm{I}(\mathrm{M}=22.31, \mathrm{SD}=5.87), \mathrm{BIS}-\mathrm{M}(\mathrm{M}=24.96, \mathrm{SD}=5.01)$, and $\mathrm{BIS}-\mathrm{P}(\mathrm{M}=$ 27.22, $\mathrm{SD}=6.83$ ).

As regard to the MMPI-2 scales, we found elevated mean scores (>64) on Schizophrenia ( $M=65, S D=14.40)$, Anxiety $(M=65, S D=13.99)$, and Obsessiveness $(M=65, S D=15.94)$ for all subjects. High mean scores were also obtained on the MAC-R $(M=68, S D=11.58)$ and $P K(M=67, S D=12.43)$ among participants. Table 1 shows the mean scores and the standard deviations for the MMPI-2 Clinical, Content, and Supplementary Scales.

Table 1. MMPI-2 mean scores

\begin{tabular}{|c|c|c|}
\hline MMPI-2 Scales & $M$ & $S D$ \\
\hline \multicolumn{3}{|l|}{ Validity Scales } \\
\hline L & 43 & 7.09 \\
\hline $\mathrm{F}$ & 68 & 17.33 \\
\hline K & 38 & 10.08 \\
\hline \multicolumn{3}{|l|}{ Clinical Scales } \\
\hline HS & 54 & 13.77 \\
\hline D & 60 & 13.66 \\
\hline Hy & 53 & 15.24 \\
\hline PD & 63 & 10.14 \\
\hline MF & 51 & 12.61 \\
\hline PA & 63 & 14.61 \\
\hline PT & 62 & 11.52 \\
\hline $\mathrm{SC}$ & 65 & 14.40 \\
\hline MA & 63 & 12.73 \\
\hline $\mathrm{SI}$ & 56 & 12.11 \\
\hline \multicolumn{3}{|l|}{ Content Scales } \\
\hline ANX & 65 & 13.99 \\
\hline FRS & 57 & 12.70 \\
\hline OBS & 65 & 13.20 \\
\hline DEP & 71 & 15.94 \\
\hline HEA & 61 & 14.79 \\
\hline $\mathrm{BIZ}$ & 64 & 16.86 \\
\hline ANG & 60 & 12.86 \\
\hline CYN & 58 & 9.63 \\
\hline ASP & 59 & 10.85 \\
\hline TPA & 58 & 10.58 \\
\hline LSE & 64 & 14.19 \\
\hline SOD & 55 & 12.00 \\
\hline FAM & 62 & 12.97 \\
\hline WRK & 67 & 15.24 \\
\hline TRT & 64 & 15.08 \\
\hline \multicolumn{3}{|c|}{ Supplementary Scales } \\
\hline $\mathrm{FB}$ & 65 & 17.98 \\
\hline MAC & 68 & 11.58 \\
\hline APS & 61 & 10.30 \\
\hline AAS & 63 & 16.51 \\
\hline PK & 67 & 12.43 \\
\hline $\mathrm{O}-\mathrm{H}$ & 41 & 7.85 \\
\hline MDS & 63 & 11.52 \\
\hline
\end{tabular}


Regarding correlations among SOGS, TAS-20, BIS, and DES, we found significant and positive interrelations among the SOGS total score and the DES $(r=.40, p<.001)$, the TAS-20/DIF $(r=.38, p<0.001)$, the BIS-Total score $(r=.45, p<$ $0.001)$, and the BIS-Motor Impulsiveness $(r=.47, p<0.001)$. Regarding the MMPI-2' scales, the SOGS correlated significantly with the PK $(r=.426, p<0.001)$, the FAM $(r=.435, p<0.001)$, the OBS $(r=.341, p<0.001)$, the DEP $(r=$ $.393, p<0.001)$, the ANX $(r=.313, p<0.001)$, MAC-R $(r=.427, p<0.001)$, and the $S c(r=.395, p<0.001)$ scales.

Linear regression analyses (stepwise Method) were performed using the SOGS as a dependent variable and all other scales (DES, TAS-20, BIS, and MMPI-2 scales) as independent variables. We obtained seven different models (see Table 2).

Table 2. Linear regression analyses with SOGS as a dependent variable and all other scales as independent variables

\begin{tabular}{|lcrc|}
\hline Model & Adjusted $\mathrm{R}^{2}$ & $\mathrm{~F}(1)$ & $\mathrm{p}$ \\
\hline 1. & .20 & 12.05 & .001 \\
2. & .34 & 12.17 & .000 \\
3. & .39 & 10.20 & .000 \\
4. & .43 & 9.14 & .000 \\
5. & .48 & 9.07 & .000 \\
6. & .54 & 9.62 & .000 \\
7. & .58 & 9.61 & .000 \\
\hline
\end{tabular}

1=IMP; $2=I M P, M A C-R ; 3=|M P, M A C-R, S|$

4=IMP, MAC-R, SI, APS, 5=IMP,MAC-R, SI, APS, ANX

$6=I M P, M A C-R, S I, A P S$, ANX, DES

On the basis of the frequency of the mean scores on the Negative Treatment Indicators (TRT) scale, 45 patients were divided into two groups; 25 (56\%) had high TRT mean scores (T scores $\geq 65$ ), and 20 (44\%) had low TRT mean scores ( $T$ scores $<65$ ). An ANOVA was performed using the group variable (T scores on TRT $\geq 65=$ group 1 ; and $T$ scores on TRT $<65=$ group 2) as independent variable and all clinical variables (TAS-20, BIS, MMPI-2) as dependent variables. Results show significant differences in mean scores for the following scales: BIS Total score $(t=-2.79, p=.008)$, TAS-20 $(t=-9.46, p=.003)$, TAS-20/DIF $(t=-5.41, p=.001), P a(t=-13.37, p=.001), P t(t=-11.49, p=.000), S c(t=-13.29, p$ $=.000)$, Si $(\mathrm{t}=-13.96, \mathrm{p}=.000)$.

\section{Discussion}

Our data confirmed the impulsive nature of pathological gambling (Odlaug, Schreiber, \& Grant, 2012). Indeed, results are significant and show positive correlations among impulsivity, dissociation and affect dysregulation (measured by the first factor of the TAS-20; see Toneatto et al., 2009; Pace et al., 2013; Craparo et al., 2013; Gori et al., 2014). In accordance with international literature about pathological gambling, we may consider the gambling disorder in rapport with dissociative defenses against traumatic affects related to a history of traumatic experiences. Moreover, in these individuals, the impulsivity might be considered as a specific type of dissociative modulation of feelings. These factors together with the psychotic features detected by the MMI-2 scales Pa and Sc, the obsessive symptoms (Pt) and the propensity towards social introversion (Si), seem associated to less therapeutic compliance and with poor outcomes.

The study has several limits, such as an insufficient number of participants and the absence of different types of gamblers. In future research it would be desirable to evaluate the presence of psychopathology (Blaszczynski \& Nower, 2002; Milosevic \& Ledgerwood, 2010) and personality traits (Tani, Ponti, Ilari, Gori \& Morisi, 2015) in different subtypes of gamblers.

\section{References}

American Psychiatric Association (2013). Diagnostic and statistical manual of mental disorders (5th ed.). Arlington, VA: American Psychiatric Publishing

Bagby, R.M., Parker, J.D.A., Taylor G.J. (1994a). The twentyitem Toronto alexithymia scale I. Item selection and crossvalidation of the factor structure. Journal of Psychosomatic Research, 38, 23-32

Bagby, R.M., Taylor, G.J., Parker, J.D.A. (1994b). The twentyitem Toronto alexithymia scale II. Convergent, discriminant, and concurrent validity. Journal of Psychosomatic Research, 38, 33-40

Blaszczynski, A., Nower, L. (2002). A pathways model of problem and pathological gambling. Addiction, 97, 487-499

Bressi, C., Taylor, G. J., Parker, J. D. A., Bressi, S., Brambilla, V., Aguglia, E. et al., (1996). Cross Validation of the Factor Structure of 
the 20 Item Toronto Alexithymia Scale: an Italian Multicenter Study. Journal of Psychosomatic Research, 41 (6), 551-559

Butcher, J. N., Dahlstrom, W. G., Graham, J. R., Tellegen, A., Kaemmer, B. (1989). Manual for the restandardized Minnesota Multiphasic Personality Inventory: MMPI-2 .(Minneapolis: University of Minnesota Press).

Craparo G., Ardino V., Gori A., Caretti V. (2013). The relationship between early trauma, dissociation, and alexithymia in alcohol addiction. Psychiatry Investigation, 11, 330-335.

Davis, C., Loxton N. J. (2013). Addictive behaviors and addiction-prone personality traits: Associations with a dopamine multilocus genetic profile. Addictive Behaviors, 38, 2306-2312

Fossati A., Di Ceglie A., Acquarini E., Barratt E.S. (2001). Psychometric properties of an Italian version of the Barratt Impulsiveness Scale-11 (BIS-11) in nonclinical subjects. Journal of Clinical Psychology, 57, 815-828.

Gori A., Craparo G., Iraci Sareri G., Caretti V., Giannini M., Meringolo P. (2014). Antisocial and Psychopathic personalities in a sample of addicted subjects: Differences in psychological resources, symptoms, alexithymia and impulsivity. Comprehensive Psychiatry, $55,1580-1586$.

Guerreschi C., Gander S. (2000). Italian version of South Oaks Gambling Screen (SOGS) (Versione italiana del South Oaks Gambling Screen (SOGS) di H.R. Lesieur e S.B. Blume, in Guerreschi C., Giocati dal gioco, San Paolo, Milano).

Lesieur, H.R., Blume, S.B. (1987). The South Oaks Gambling Screen (SOGS): A new intrument of the identification of pathological gamblers. American Journal of Psychiatry, 144, 1184-1188.

Lorains, F.K., Cowlishaw, S., Thomas S.,A. (2012). Prevalence of comorbid disorders in problem and pathological gambling: systematic review and meta-analysis of population surveys. Addiction, 106, 490-498

Milosevic, A., \& Ledgerwood, D.M. (2010). The subtyping of pathological gambling: A comprehensive review. Clinical Psychology Review, 30, 988-998

Odlaug, L. B., Schreiber R. N., Grant J. E. (2012). Personality Disorders and Dimensions in Pathological Gambling. Journal of Personality Disorders 26, 3, 381-392

Pace U., Schimmenti A., Zappulla C., Di Maggio R. (2013). Psychological variables cahracterizing different types of adolescent gamblers: A discriminant function analysis. Clinical Neuropsychiatry, 10, 253-259.

Pancheri, P., Sirigatti, S. (a cura di) (1995). MMPI-2 - Minnesota Multiphasic Personality Inventory - 2. Manuale. Firenze: Giunti O.S. Organizzazioni Speciali

Patton, J. H., Stanford, M. S., Barratt, E. S. (1995). Factor structure of the Barratt Impulsiveness Scale. Journal of Clinical Psychology, 51(6), 768-774

Quigley, L., et al., (2014). Comorbid Problem Gambling and Major Depression in a Community Sample. Journal of Gambling Studies. 10.1007/s10899-014-9488-8

Suomi, A., Dowling, N.A., Jackson, A.C. (2014). Problem gambling subtypes based on psychological distress, alcohol abuse and impulsivity. Addictive Behaviors, 39, 12, 1741-1745

Tani, F, Ponti, L, Ilari, A, Gori, A, Morisi, M (2015).Personality characteristics of pathological gamblers. Poster presented at the InPACT 2015 - International Psychological Applications Conference an Trends congress. Ljubjana, Slovenia 2-4 May.

Toneatto, T, Lecce, J, Bagby, M (2009) Alexithymia and pathological gambling. Journal of Addiction Disorders, 28,193-198 